\title{
Associations between maternal responsive linguistic input and child language performance at age 4 in a community-based sample of slow-to-talk toddlers
}

Short title: Mother-child interaction and child language

Authors: Penny Levickis, $\mathrm{PhD}^{1,2}$, Sheena Reilly, $\mathrm{PhD}^{2,3,4}$, Luigi Girolametto, $\mathrm{PhD}^{5}$, Obioha C Ukoumunne, $\mathrm{PhD}^{6}$, Melissa Wake, $\mathrm{MD}^{2,4,7}$

Institutions: $\quad{ }^{1}$ Newcastle University, Newcastle upon Tyne, UK

${ }^{2}$ Murdoch Childrens Research Institute, Parkville, Australia

${ }^{3}$ Menzies Health Institute Queensland, QLD, Australia

${ }^{4}$ University of Melbourne, Melbourne, Australia

${ }^{5}$ Department of Speech-Language Pathology, University of Toronto, Toronto, Canada

${ }^{6}$ NIHR CLAHRC South West Peninsula (PenCLAHRC), University of Exeter Medical School, Exeter, UK

${ }^{7}$ Department of Paediatrics and the Liggins Institute, The University of Auckland, Auckland, New Zealand

Correspondence to: Dr Penny Levickis

Newcastle University

School of Education, Communication \& Language Sciences

Queen Victoria Rd, Newcastle upon Tyne, NE1 7RU

This is the author manuscript accepted for publication and has undergone full peer review but has not been through the copy (Q), 191,2085120, Email penny, levickis @ newcastle, ac, uk may lead to differences between this version and the Version of Record. Please cite this article as doi: $10.1111 /$ cch.12600

Word Count: $\quad 2,959$

This article is protected by copyright. All rights reserved. 
Keywords:

maternal responsiveness, child language, longitudinal, population research, slow-to-talk toddlers

\section{Additional Author Details:}

Penny Levickis $\mathrm{PhD}$

Marie Skłodowska-Curie Fellow

Newcastle University

Queen Victoria Rd, Newcastle upon Tyne, NE1 7RU

$\mathrm{T}+44(0) 1912085120$

Email penny.levickis@newcastle.ac.uk

\section{Sheena Reilly $\mathrm{PhD}$}

Pro Vice Chancellor (Health)

Gold Coast Campus

Griffith University

QLD, Australia 4222

T: +61 756780711

Emails.reilly@griffith.edu.au

\section{Luigi Girolametto $\mathrm{PhD}$}

Professor, Department of Speech-Language Pathology

Rehabilitation Sciences Building

Faculty of Medicine, University of Toronto

160-500 University Avenue

Toronto, ON, Canada M5G 1V7

T: +4169465456

Email 1.girolametto@utoronto.ca

\section{Obioha C Ukoumunne PhD}

Associate Professor, Medical Statistics

South Cloisters

University of Exeter, St Luke's Campus 
Heavitree Rd

Exeter, UK EX1 2LU

T: $+44(0) 1392726070$

Email O.C.Ukoumunne@exeter.ac.uk

\author{
Melissa Wake MD \\ Centre for Community Child Health, Murdoch Childrens Research Institute \\ Flemington Road, \\ Parkville, VIC 3052, Australia \\ T: +6139345 5937 \\ Email melissa.wake@mcri.edu.au
}

\title{
ACKNOWLEDGEMENTS
}

Let's Learn Language (NHMRC Strategic Award 384491) and Language for

Learning (Project Grant 607407) were funded by the Australian National Health and Medical Research Council. The authors thank the Let's Learn Language and Language for Learning study teams and all participating families, as well as Carly Vaness who carried out the interrater reliability for the current study. Dr Levickis was supported by the European Union's Horizon 2020 research and innovation programme under the Marie Sklodowska-Curie grant agreement No. 705044. The authors acknowledge the support of the NHMRC-funded Centre of Research Excellence in Child Language (\#1023493): Prof Wake (Senior Research Fellowship 1046518) and Prof Reilly (Practitioner Fellowship 1041892). Dr Obi Ukoumunne is funded by the National Institute for Health Research (NIHR) Collaboration for Leadership in Applied Health Research and Care (CLAHRC) for the South West Peninsula at the Royal Devon and Exeter NHS Foundation Trust. The views expressed in this publication are those of the authors and not necessarily those of the NHRMC, the NHS, the NIHR or the Department of Health in England. Research at the Murdoch Childrens Research Institute is supported by the Victorian Government's Operational Infrastructure Support Program. The researchers were independent of the funders.

Declaration of interest: The authors report no conflicts of interest. The authors are responsible for the content and writing of the paper. 
Associations between maternal responsive linguistic input and child language performance at age 4 in a community-based sample of slow-to-talk toddlers

Short title: Mother-child interaction and child language

Authors: Penny Levickis, $\mathrm{PhD}^{1,2}$, Sheena Reilly, $\mathrm{PhD}^{2,3,4}$, Luigi Girolametto, $\mathrm{PhD}^{5}$, Obioha C Ukoumunne, $\mathrm{PhD}^{6}$, Melissa Wake, $\mathrm{MD}^{2,4,7}$

\footnotetext{
Institutions: $\quad{ }^{1}$ Newcastle University, Newcastle upon Tyne, UK

${ }^{2}$ Murdoch Childrens Research Institute, Parkville, Australia

${ }^{3}$ Menzies Health Institute Queensland, QLD, Australia

${ }^{4}$ University of Melbourne, Melbourne, Australia

${ }^{5}$ Department of Speech-Language Pathology, University of Toronto, Toronto,

Canada

${ }^{6}$ NIHR CLAHRC South West Peninsula (PenCLAHRC), University of Exeter Medical School, Exeter, UK

${ }^{7}$ Department of Paediatrics and the Liggins Institute, The University of Auckland, Auckland, New Zealand
}

Correspondence to: Dr Penny Levickis

Newcastle University

School of Education, Communication \& Language Sciences

Queen Victoria Rd, Newcastle upon Tyne, NE1 7RU

Ph +44 (0) 1912085120 Email penny.levickis@ newcastle.ac.uk

\section{Word Count: $\quad 2,959$}


Keywords: maternal responsiveness, child language, longitudinal, population research, slow-to-talk toddlers

\section{Additional Author Details:}

\section{Penny Levickis $\mathrm{PhD}$}

Marie Skłodowska-Curie Fellow

Newcastle University

Queen Victoria Rd, Newcastle upon Tyne, NE1 7RU

$\mathrm{T}+44(0) 1912085120$

Email penny.levickis@newcastle.ac.uk

\section{Sheena Reilly $\mathrm{PhD}$}

Pro Vice Chancellor (Health)

Gold Coast Campus

Griffith University

QLD, Australia 4222

T: +61 756780711

Emails.reilly@griffith.edu.au

\section{Luigi Girolametto $\mathrm{PhD}$}

Professor, Department of Speech-Language Pathology

Rehabilitation Sciences Building

Faculty of Medicine, University of Toronto

160-500 University Avenue

Toronto, ON, Canada M5G 1V7

$\mathrm{T}:+4169465456$

Email1.girolametto@utoronto.ca 
Obioha C Ukoumunne $\mathrm{PhD}$

Associate Professor, Medical Statistics

South Cloisters

University of Exeter, St Luke's Campus

Heavitree Rd

Exeter, UK EX1 2LU

T: +44 (0) 1392726070

Email O.C.Ukoumunne@exeter.ac.uk

\section{Melissa Wake MD}

Centre for Community Child Health, Murdoch Childrens Research Institute

Flemington Road,

Parkville, VIC 3052, Australia

T: +6139345 5937

Email melissa.wake@mcri.edu.au

\section{ACKNOWLEDGEMENTS}

Let's Learn Language (NHMRC Strategic Award 384491) and Language for Learning (Project Grant 607407) were funded by the Australian National Health and Medical Research Council. The authors thank the Let's Learn Language and Language for Learning study teams and all participating families, as well as Carly Vaness who carried out the inter-rater reliability for the current study. Dr Levickis was supported by the European Union's Horizon 2020 research and innovation programme under the Marie Sklodowska-Curie grant agreement No. 705044. The authors acknowledge the support of the NHMRC-funded Centre of Research Excellence in Child Language (\#1023493): Prof Wake (Senior Research Fellowship 1046518) and Prof Reilly (Practitioner Fellowship 1041892). Dr Obi Ukoumunne is funded by the National Institute for Health Research (NIHR) Collaboration for Leadership in Applied Health Research and Care (CLAHRC) for the South West Peninsula at the Royal Devon and Exeter NHS Foundation Trust. The views expressed in this publication are those of the authors and not necessarily those of the NHRMC, the NHS, the NIHR or the Department of Health in England. Research at the Murdoch 
Childrens Research Institute is supported by the Victorian Government's Operational Infrastructure Support Program. The researchers were independent of the funders.

Declaration of interest: The authors report no conflicts of interest. The authors are responsible for the content and writing of the paper.

\begin{abstract}
Background: In a community sample of slow-to-talk toddlers, we aimed to (1) quantify how well maternal responsive behaviours at age 2 years predict language ability at age 4 , and (2) examine whether maternal responsive behaviours more accurately predict low language status at age 4 than does expressive vocabulary measured at age 2 years.
\end{abstract}

Design/Methods: Prospective community-based longitudinal study. At child age 18 months, 1138 parents completed a 100-word expressive vocabulary checklist within a population survey; 251 $(22.1 \%)$ children scored $\leq 20$ th percentile and were eligible for the current study. Potential predictors at 2 years were: (1) responsive language behaviours derived from videotaped parent-child free-play samples; and (2) late-talker status. Outcomes were (1) CELF-P2 receptive and expressive language standard score at 4 years and (2) low language status (standard score $>1.25$ standard deviations below the mean on expressive or receptive language).

Results: 208 (82.9\% of 251) participants were retained to age 4. In adjusted linear regression analyses, maternal expansions predicted higher receptive $\left(p<0.001\right.$, partial $\left.\mathrm{R}^{2}=6.5 \%\right)$ and expressive ( $p<0.001$, partial $\left.\mathrm{R}^{2}=7.7 \%\right)$, while labels predicted lower receptive $\left(p=0.01\right.$, partial $\left.\mathrm{R}^{2}=2.8 \%\right)$ and expressive ( $p=0.007$, partial $\mathrm{R}^{2}=3.5 \%$ ) language scores at 4 . The logistic regression model 
containing only responsive behaviours achieved 'fair' predictive ability of low language status at age 4 (area under curve (AUC) 0.79), slightly better than the model containing only late-talker status (AUC $=0.74)$. This improved to 'good' predictive ability with inclusion of other known risk factors $(\mathrm{AUC}=0.82)$.

Conclusion: A combination of short measures of different dimensions, such as parent responsive behaviours, in addition to a child's earlier language skills increases the ability to predict language outcomes at age 4 to a precision that is approaching clinical value. Research to further enhance predictive values should be a priority, enabling health professionals to identify which slow-to-talk toddlers most likely will/will not experience later poorer language.

\section{Key Messages}

- Neither traditional risk factors nor early language screening tools accurately predict which toddlers will go on to have language difficulties in the preschool years.

- This population-derived study provides some of the strongest evidence to date for an association between maternal use of expansions and labels at age 2 with higher and lower language outcomes at age 4 respectively.

- A combination of short measures associated with child language (such as maternal responsive behaviours) increases the ability to predict language outcomes at age 4, providing optimism that further research could enhance predictive values to be of clinical value. 


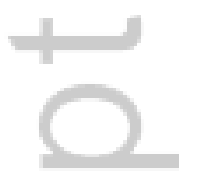

4 


\section{INTRODUCTION}

Language difficulties affect one in five pre-schoolers (Reilly et al. 2010). Long-term ramifications at the population level include deficits in academic performance (Young et al. 2002; Law et al. 2009), adolescent attention and social difficulties (Snowling et al. 2006), reduced employment opportunities (Law et al. 2009), and poorer adult mental health (Law et al. 2009). Thus, a persistent language difficulty can be of great financial burden to individuals and families, as well as to society as a whole (Sciberras et al. 2015).

According to a 2016 Lancet Series on early childhood development, there is now a strong economic case for investing in the early years, with a need for preventative interventions to ensure children reach their developmental potential (Lo et al. 2017; Black et al. 2017). Further, a recent review identified promising preventative interventions for children at risk of persistent language difficulties (Law et al. 2017). Although early identification and preventative intervention is therefore highly desirable, it has proven very problematic. High levels of natural resolution and fluctuation mean it remains challenging to accurately target resources at age 2 to those most likely to have later problems, e.g. at age 4 (Reilly et al. 2010). Neither traditional risk factors nor early language screening tools accurately predict which toddlers will go on to have language difficulties in the preschool years (Law et al. 2012; Reilly et al. 2010; Wallace et al. 2015). Of particular concern is that sensitivity (i.e. identifying children who go on to develop a language disorder) is typically poor when using a single core language or vocabulary measure in toddlerhood (Law et al. 2012). As a result children who might benefit most from intervention slip through the cracks.

An alternative approach to screens that focus on child language is to consider novel predictors of language outcomes (Ellis \& Thal 2008) such as maternal responsive behaviours, defined as 
contingent, appropriate and prompt parent responses to a child's initiations (Bornstein \& TamisLeMonda 1989). Both empirical and theoretical research support their important role in early child language development. During infancy parent behaviours that are contingent and responsive to a child's communicative acts, such as babbling or gesturing, promote turn taking and facilitate infant word-referent mapping, supporting vocabulary growth (Tamis-LeMonda et al. 2014). Semantically contingent responses to a child's focus of attention are thought to provide an optimal learning environment; decreasing the demands on a child's attention and cognitive functions allows the child to readily process information produced by the parent (Hebert et al. 2004; McGillion et al. 2013). Such behaviours include maternal use of labels, imitations, expansions and questions. All have been shown to predict the timing of toddlers achieving expressive language milestones (Tamis-LeMonda et al. 2001) and child vocabulary and expressive language outcomes (Taumoepeau 2016;

Girolametto et al. 1999; Tomasello \& Farrar 1986). Maternal responsive behaviours at age 2 years are also strongly associated with children's language cross-sectionally and in short-term follow-up at the population level (*removed for blind review).

The arduous task of recording and coding parent-child interactions has been a major obstacle to measuring maternal behaviours at the population level (Gardner 2000). However, new technology has yielded techniques that are feasible, efficient and reliable at the population level (*removed for blind review). We report on a population-based study that measured both maternal responsive behaviours and language in slow-to-talk toddlers at age 2 years and their language outcomes at age 4 years. In this paper, we aimed to:

1. Prospectively quantify the degree to which mothers' responsive language at 2 years predicts language outcomes at age 4 , and 
2. Investigate whether maternal responsive behaviours more accurately predict low language status at age 4 years than parent-report expressive vocabulary measured at age 2 years using the 100-word Sure Start language measure.

\section{METHODS}

\section{Study design and participants}

This prospective longitudinal study involved mother-child dyads recruited as part of the *removed for blind review randomised controlled trial. The children are treated here as a single cohort, because the trial had robustly null results with no trend to an intervention effect (adjusted mean difference between intervention and control children at age 3 years: $-2.4, \mathrm{CI}-6.2$ to $1.4, \mathrm{p}=0.21$ expressive; -0.3, CI -4.2 to 3.7, $\mathrm{p}=0.90$ receptive) (see Wake et al. 2011 for intervention details). We selected three local government areas in (*removed for blind review) to span the full socioeconomic range from disadvantaged to advantaged, with all children born May-December 2006 eligible for enrolment. Parents of infants attending their routine 12 month check were invited by their nurse to participate. Parents provided written informed consent, and the study was approved by the (*removed for blind review).

At child age 18 months, 1138 of the 1217 (93.5\%) parents recruited at child age 12 months completed a 100-word expressive vocabulary checklist (Sure Start Language Measure: Roy, Kersley \& Law 2005). 251 (22.1\%) children scored $\leq 20$ th percentile for expressive vocabulary and were eligible for this study, providing a sample likely to be enriched for both being late talkers at 2 years and having low language at 4 . We excluded children with known pre-existing medical 
conditions, cognitive delay or parents unable to complete questionnaires in English at a Grade 6 (11 year old) reading level.

\section{Procedures}

Data required for this study (parent-child interaction data at age 2 and language outcomes at age 4) were available on 204 (81.3\%) of the 251 eligible slow-to-talk toddlers. At age 2, trained research assistants visited the home for a 60-minute language assessment (Preschool Language Scale, $4^{\text {th }}$ edition: Zimmerman, Steiner $\&$ Pond 2002) with the child, blind to trial arm status. Mother-child dyads were also video recorded during 15 minutes of free-play. The researcher provided two sets of toys (a farm and nurturing set) and the mother was instructed to play with her child as she normally would. At age 4, a further blinded language assessment was conducted in the home.

\section{Measures}

\section{Predictors at age 2: Maternal responsive behaviours and expressive vocabulary}

An extensive review of the literature identified six responsive behaviours considered most likely to predict child language outcomes at 2 and 3 years (see *excluded for blind review), comprising: expansions (Girolametto et al. 1999; Lasky \& Klopp 1982), imitations (Girolametto et al. 1999; Lasky \& Klopp 1982) interpretations (Girolametto et al. 1999), labels (Girolametto et al. 1999; Namy \& Nolan 2004), supportive directives (Masur et al. 2005) and responsive questions (TamisLeMonda et al. 2001). Four of these behaviours (expansions, imitations, labels and responsive questions) were retained for the current analyses because our previous findings showed associations 
with language outcomes (*removed for blind review). The other two behaviours (supportive directives and interpretations) were not associated with child language outcomes.

Table 1 provides an overview of the study's coding scheme, as well as the frequency of responsive behaviours for the sample. Maternal responsive behaviours were coded from the middle 10 minutes of each videotaped observation using the Observer ${ }^{\circledR}$ XT software (Noldus Information Technology 2008), with all expressed as rate per minute. Intra- and inter-rater reliability showed very high intra-class correlation coefficients of 0.95 to 0.99 for all four behaviours.

At age 2 years parents completed the 100-word Sure Start language measure (Roy, et al. 2005), a parent-reported measure of expressive vocabulary. The Sure Start measure is adapted from the MacArthur-Bates Communicative Development Inventory: UK short form (MCDI-UK short form) (Dale et al. 2003), which is a widely used (both nationally and internationally) and accepted parentreported measure of child productive vocabulary (Fenson, et al. 1994).

\section{Child language outcomes at age 4}

At age 4 years, the Clinical Evaluation of Language Fundamentals-Preschool Second Edition (CELF-P2) (Semel et al. 2006) was administered, providing receptive and expressive language standard scores. The CELF-P2 is widely used, norm-referenced and standardised to a mean of 100 (SD 15).

\section{Potential confounders, selected a priori}

Potential confounders were the *removed for blind peer review trial arm status and several baseline variables, i.e., gender, birth order, age at follow-up, maternal education, and SEIFA (Socio- 
Economic Indexes for Areas) disadvantage index score (*removed for blind peer review mean, 1000; SD, 100) for the family's postcode of residence. SEIFA scores are derived from the *removed for blind peer review Census, with a higher score indicating a less disadvantaged neighbourhood relative to other areas (*removed for blind peer review).

\section{Analyses}

All analyses were conducted using Stata 14 (StataCorp 2015). Linear regression was used to examine the relationship between each of the four responsive behaviours and language outcomes (receptive and expressive language scores) at age 4 years (aim 1). Responsive behaviours were included as predictor variables (continuous) one at a time in separate unadjusted (crude) regression analyses to determine if the responsive behaviours predicted language scores (continuous) over and above the potential confounders.

For aim 2, we first determined the 'optimal' cut-off value of the most highly-predictive maternal responsive behaviours in predicting low language status at age 4 . We constructed ROC curves using the 'roctab' command in Stata 14 (StataCorp 2015). The ROC curve is a plot of sensitivity (true positive rate on the $Y$ axis) against 1-specificity (false positive rate on the $X$ axis) at each possible cut-off value of the predictor variable; the closer to the upper left corner, the better the predictive ability of the test (Linnet et al. 2012). Kirkwood and Sterne (2003) define acceptable levels of sensitivity and specificity to be greater than $70 \%$. In order to maximise sensitivity and specificity, the cut-off value was determined as the cutpoint in the ROC curve closest to $(0,1)$ (i.e., the point with perfect sensitivity and specificity). 
Late talker status was defined using the commonly used cut-off of below the $10^{\text {th }}$ percentile on the parent-reported expressive vocabulary measure at age 2. 'Not a late talker' was coded as 0; 'Late talker' was coded as 1 . The outcome variable of low language status at age 4 was defined using a score of $>1.25$ standard deviations below the mean for expressive or receptive language on the CELF-P2 (Reilly et al. 2010). 'Not low language status' was coded 0; 'Low language status' was coded as 1 .

Next, logistic regression analysis was run to examine how the dichotomised maternal responsive behaviours and late-talker status predicted low language status at age 4. As predictors, the first model included late-talker status, the second model included the two predictive dichotomised maternal responsive behaviours (expansions and labels), and the third model included both latetalker status and the two maternal responsive behaviours. The final model adjusted the combined third model for the predictive risk factors identified in the Early Language in Victoria Study, which quantified the contributions of child, family and environmental factors to child language at age 4 years (Reilly et al 2010). Risk factors included child gender, prematurity, birth weight and order, multiple birth, socioeconomic status, maternal education, and age at child's birth, non-English speaking background and family history of language difficulties.

The area under the curve (AUC) was calculated to quantify the ability of each regression model to discriminate between those children with low language at age 4 and those with typical language at age 4. Higher AUC values suggest better discriminatory abilities as follows: 0.61-0.69, poor validity; 0.70-0.79, fair validity; 0.80-0.89, good validity; and $\geq 0.9$, excellent validity (Kirkwood \& Sterne 2003). 


\section{RESULTS}

Table 2 shows the characteristics of the mothers and children followed up at age 4 compared to those who were not followed up. Of the 251 parent-child dyads that provided video data at age 2 years, $204(81.3 \%)$ provided outcome data at age 4 years. Just under half of the children followed up at age 4 were girls, the average age of mothers was 33 years, mother-child dyads were slightly less disadvantaged than the average Australian family and almost all toddlers lived with both parents $(95.2 \%, 198 / 208)$. In this sample of slow-to-talk toddlers, the average number of words reported by parents at age 2 years on the 100 word checklist was $34.8(\mathrm{SD}=22.5)$. At 4 years of age, $22.6 \%$ (46/204) scored >1.25 SD below the mean on CELF-P2 expressive or receptive subtests (Reilly et al. 2010) and were defined as having the outcome of low language at age 4 years.

The unadjusted and adjusted linear regression models of receptive and expressive language outcomes on each maternal responsive behaviour separately are presented in table 3 (aim 1). Associations changed only marginally from the unadjusted to adjusted models. Imitations showed little association and responsive questions showed only weak predictive associations with receptive (coefficient: 3.5 ; CI: -0.1 to $7.1 ; \mathrm{p}=0.06$; partial $\mathrm{R}^{2}=1.8 \%$ ) and expressive (coefficient: 3.5 ; $\mathrm{CI}$ : -0.1 to $7.0 ; \mathrm{p}=0.06$; partial $\mathrm{R}^{2}=1.9 \%$ ) language at age 4 . However, more expansions strongly predicted higher receptive (coefficient: 6.1; CI: 2.8 to 9.3; $\mathrm{p}<0.001$; partial $\mathrm{R}^{2}=6.5 \%$ ) and expressive (coefficient: 6.5; CI: 3.3 to 9.7; $\mathrm{p}<0.001$; partial $\mathrm{R}^{2}=7.7 \%$ ) scores, while more labels predicted lower receptive (coefficient: -3.4 ; CI: -6.3 to $-0.6 ; \mathrm{p}=0.02$; partial $\mathrm{R}^{2}=2.8 \%$ ) and expressive (coefficient: -3.7 ; CI: -6.6 to -0.9 ; $\mathrm{p}=0.01$; partial $\mathrm{R}^{2}=3.5 \%$ ) scores.

For aim 2 we included the two maternal behaviours (expansions and labels) that were shown in the results for aim 1 above to predict expressive and receptive language outcomes at age 4 , over and 
above potential confounding variables. Based on ROC analysis, we dichotomised these variables at their optimal cut off points of 0.4 expansions/minute (equating to sensitivity of $71 \%$ and specificity of $64 \%$ ) and 1.1 labels/minute (equating to sensitivity of $71.1 \%$ and specificity of $55.6 \%$ ); in other words, sensitivity just reached acceptable levels, while specificity fell short (noting that the sample in this study overrepresented children with lower expressive vocabulary). The dichotomised variables were then entered into logistic regression analyses, as was the late-talker status variable.

Table 4 shows results for each of these logistic regression models. The odds of low language at age 4 increased significantly if the child was a late-talker at age 2 (OR: 5.4; 95\% CI: 2.6 to 11.4; $\mathrm{p}<0.001)$. The second model shows that high use of maternal expansions significantly reduced (OR: 0.26; $95 \%$ CI: 0.12 to $0.54 ; \mathrm{p}<0.001$ ), while high use of labels at age 2 increased (OR: 2.6 ; $95 \%$ CI: 1.3 to $5.5 ; \mathrm{p}=0.01$ ) the likelihood of a child having low language at age 4 . When including all together in Model 3, both late-talker status (OR: 2.9; 95\% CI: 1.2 to $6.9 ; \mathrm{p}=0.02$ ) and expansions (OR: $0.43 ; 95 \%$ CI: 0.18 to $1.04 ; \mathrm{p}=0.06$ ) attenuated; however, use of labels did not attenuate (OR: 2.8; $95 \%$ CI: 1.3 to 6.2; $\mathrm{p}=0.01$ ). After further adjusting for known risk factors (Model 4), latetalker status attenuated to no longer independently predict low language at age 4 (OR: $2.3 ; 95 \% \mathrm{CI}$ : 0.82 to $6.3 ; \mathrm{p}=0.1$ ). However, neither of the responsive behaviours attenuated further; use of expansions remained protective (OR: $0.35 ; 95 \%$ CI: 0.13 to $1.0 ; p=0.05)$, while high use of labels actually strengthened to greatly increase the odds of low language four-fold at age 4 (OR: 4.5; $95 \%$ CI: 1.7 to $11.9 ; \mathrm{p}<0.003)$.

The area under the curve for responsive behaviours signified only fair discrimination between children with and without low language status (Model 2, 0.72) - slightly better discrimination than late-talker status alone (Model 1, 0.67). Combining responsive behaviours with late talking status 
and then further adjusting for risk factors progressively strengthened discrimination, to 0.74 (Model 3) and 0.82 (Model 4) respectively, reaching Kirkwood \& Sterne's criterion of 0.80 for 'good' discrimination in the final model.

\section{DISCUSSION}

There is growing support for identifying factors that may be measured in the early years, alone or in combination, to identify children who will benefit from early intervention (McKean et al. 2016). Maternal responsive behaviours (specifically expansions and labels) measured at age 2 years predicted both expressive and receptive language scores at age 4 years in this sample of slow-to-talk toddlers. Responsive behaviours and late-talker status performed similarly in discriminating between children with low language and normal language scores at age 4 years, providing fair and poor predictive precision respectively. Combining them in the same model provided moderate predictive precision and, when combined with the risk factors, the model improved further to provide good discrimination.

The finding that maternal labels were associated with poorer expressive language is in contrast to previous studies, which generally showed either no association or a positive association, i.e., more labels predicted better language outcomes (Tomasello \& Todd 1983; Yoder et al. 1998). As maternal labels are a response to a child's focus of attention (Yoder et al. 1998) and not dependent on a child's preceding verbalisation, these findings may actually be an instance of reverse causation in that by age 2 years they may reflect on the child's low language ability (i.e., the child is producing less language and providing fewer opportunities for the mother to respond). While labels may be positive and promote language at the preverbal and single-word stage of language 
development in infants and young toddlers (Namy \& Nolan 2004; Yoder et al. 1998), by age 2 years they may be a sign that the child is behind.

Strengths: This large community-based sample not only confirms but goes beyond previous studies (Girolametto et al. 2002; Tamis-LeMonda et al. 2001; McDuffie \& Yoder 2010; *removed for peer review) in supporting a positive relationship between the use of expansions with child language outcomes in a sample likely to be more representative. Previous findings for a number of the responsive behaviours examined (i.e., labels and responsive questions) have not been definitive because studies have included either small samples of typically developing children or samples of children presenting clinically with severe language deficits, as well as including mother-child dyads from relatively homogeneous backgrounds.

Limitations: This study only included children who were slow to start talking at 18 months of age, so caution must be taken when interpreting the results. However, by age 4 years they had a wide range of outcomes (mean (SD), range: 94.0 (14.1), 56 to 130; and 97.3 (14.4), 50 to 138 for receptive and expressive language respectively). This offered a large sample of children with varying language abilities, resulting in the potential to establish the predictive power of responsive behaviours beyond the current evidence-base. Non-English speaking families were excluded from the current study, although families with adequate English but for whom English was not their first language could participate. Therefore, findings may not fully generalise to non-English speaking families. In addition, more socio-economically disadvantaged mother-child dyads were slightly underrepresented. This could threaten generalisability, given the substantial evidence suggesting that the quality and quantity of parent-child interaction mediates the association between socioeconomic status and language development. However, there is empirical evidence demonstrating 
that exposure-outcome associations in longitudinal studies are relatively robust to deviations from representativeness (Nohr et al. 2006; Nilsen et al. 2009).

Interpretation: Identification of those most at risk of persistent language problems via a one-off measure has thus far not proved helpful (Wake et al. 2011; Reilly et al. 2010). That lower maternal expansions may in fact be an indirect measure of poorer language production at age 2 years is supported by our finding that, when included with late talker status, the power of both variables to predict low language at age 4 years attenuated. Likewise, maternal use of labels may in fact be a marker for a parent's intuitive recognition that their child is at a much lower stage of language acquisition than would benefit from more 'advanced' responsive inputs, i.e., the child is already on a poor pathway. Models including all of late talking status, maternal responsive behaviours and known risk factors for low language provided the strongest prediction and good discrimination. The area under the curve was similar to that reported at age 4 in the Early Language in Victoria Study of 0.78-0.84 using known risk factors and late talking status alone in a normally-developing community sample (Reilly et al. 2010). This provides optimism that even better predictive models may yet be developed. An important next step could be to examine the added discriminatory power of maternal responsive behaviours to a combined language risk-factor model in a population-based sample including the full range of toddler language ability. Understanding a child's exposure to maternal responsive behaviours may assist practitioners to identify those children most likely to have poorer later language. In addition, findings from the current study support teaching and encouraging primary caregivers to use responsive behaviours, such as expansions, to assist child language development. Such behaviours could be promoted through existing early child health services such as 2 year old child and family health nurse checks. 
Conclusions: A combination of short measures of different dimensions, such as parent responsive behaviours, in addition to a child's earlier language skills increases the ability to predict language outcomes at age 4 to a precision that is approaching clinical value. Research to further enhance predictive values should be a priority, enabling health professionals to identify which slowto-talk toddlers most likely will/will not experience poor language later.

This article is protected by copyright. All rights reserved. 


\section{References}

Black, M. M., Walker, S. P., Fernald, L. C., Andersen, C. T., DiGirolamo, A. M., Lu, C., ... \& Devercelli, A. E. (2017) Early childhood development coming of age: science through the life course. The Lancet, 389(10064), 77-90.

Bornstein, M. H., \& Tamis-LeMonda, C. S. (1989) Maternal responsiveness and cognitive development in children. New Directions for Child and Adolescent Development, 43, 49-61.

Dale PS, Price TS, Bishop DVM, Plomin R. (2003) Outcomes of early language delay: I. predicting persistent and transient language difficulties at 3 and 4 years. J Speech Lang Hear Res. 46(3), 544-60.

Ellis, E. M., \& Thal, D. J. (2008) Early language delay and risk for language impairment. SIG 1 Perspectives on Language Learning and Education, 15(3), 93-100.

Fenson, L., Dale, P.S., Reznick, J.S., Bates, E., Thal, D.J., \& Pethick, S.J. (1994) Variability in early communicative development. Monogr Soc Res Child Dev. 59(5), 1-173.

Girolametto, L., Weitzman, E., Wiigs, M., \& Pearce, P. S. (1999) The relationship between maternal language measures and language development in toddlers with expressive vocabulary delays. American Journal of Speech-Language Pathology, 8(4), 364-374.

Kirkwood, B. J., \& Sterne, J. A. C. (2003) Essential Medical Statistics (2 ${ }^{\text {nd }}$ ed.). Oxford, England: Blackwell Sciences.

Lasky, E. Z., \& Klopp, K. (1982) Parent-child interactions in normal and language-disordered children. Journal of Speech and Hearing Disorders, 47(1), 7-18.

This article is protected by copyright. All rights reserved. 
Law, J., Rush, R., Schoon, I., \& Parsons, S. (2009) Modeling developmental language difficulties from school entry into adulthood: Literacy, mental health, and employment outcomes. Journal of Speech, Language, and Hearing Research, 52(6), 1401-1416.

Law, J., Rush, R., Anandan, C., Cox, M., \& Wood, R. (2012) Predicting language change between 3 and 5 years and its implications for early identification. Pediatrics, 130(1), e132-e137.

Law, J. Charlton, J., Dockrell, J., Gascoigne, M., Mckean, C., \& Theakston, A. (2017). Early Language Development: Needs, provision and intervention for preschool children from socioeconomically disadvantage backgrounds. London: Education Endowment Foundation.

Linnet, K., Bossuyt, P. M., Moons, K. G., \& Reitsma, J. B. (2012) Quantifying the accuracy of a diagnostic test or marker. Clinical chemistry, 58(9), 1292-1301.

Lo, S., Das, P., \& Horton, R. (2017) A good start in life will ensure a sustainable future for all. Lancet, 389(10064), 8.

McDuffie, A., \& Yoder, P. (2010) Types of parent verbal responsiveness that predict language in young children with autism spectrum disorder. Journal of Speech, Language, and Hearing Research, 53(4), 1026-1039.

McGillion, M. L., Herbert, J. S., Pine, J. M., Keren-Portnoy, T., Vihman, M. M., \& Matthews, D. E. (2013) Supporting early vocabulary development: What sort of responsiveness matters? IEEE Transactions on Autonomous Mental Development, 5(3), 240-248.

Masur, E. F., Flynn, V., \& Eichorst, D. L. (2005) Maternal responsive and directive behaviours and utterances as predictors of children's lexical development. Journal of Child Language, 32(1), 63-91.

This article is protected by copyright. All rights reserved. 
Namy, L. L., \& Nolan, S. A. (2004) Characterizing changes in parent labelling and gesturing and their relation to early communicative development. Journal of child language, 31(4), 821835.

Nilsen, R. M., Vollset, S. E., Gjessing, H. K., Skjaerven, R., Melve, K. K., Schreuder, P., Alsaker, E. R., Haug, K., Daltveit, A. K., \& Magnus, P. (2009) Self-selection and bias in a large prospective pregnancy cohort in Norway. Paediatric and perinatal epidemiology, 23(6), 597608.

Nohr EA, Frydenberg M, Henriksen TB, Olsen J. (2006) Does low participation in cohort studies induce bias? Epidemiology. 17(4), 413-418.

Noldus Information Technology. (2008) The Observer XT. Wageningen, the Netherlands: Noldus Information Technology b.v.

Reilly, S., Wake, M., Ukoumunne, O.C., Bavin, E., Prior, M., Cini, E., Conway, L., Eadie, P. \& Bretherton, L. (2010) Predicting language outcomes at 4 years of age: findings from Early Language in Victoria Study. Pediatrics, 126(6), e1530-7.

Sciberras, E., Westrupp, E. M., Wake, M., Nicholson, J. M., Lucas, N., Mensah, F., Gold, L. \& Reilly, S. (2015) Healthcare costs associated with language difficulties up to 9 years of age: Australian population-based study. International journal of speech-language pathology, 17(1), 41-52.

Semel, E. M., Wiig, E. H., \& Secord, W. (2006) CELF 4: clinical evaluation of language Fundamentals. Pearson: Psychological Corporation. 
Snowling, M. J., Bishop, D. V. M., Stothard, S. E., Chipchase, B., \& Kaplan, C. (2006) Psychosocial outcomes at 15 years of children with a preschool history of speech-language impairment. Journal of Child Psychology and Psychiatry, 47(8), 759-765.

StataCorp. (2015) Stata Statistical Software: Release 14. College Station, TX: StataCorp LP.

Tamis-LeMonda, C. S., Bornstein, M. H., \& Baumwell, L. (2001). Maternal responsiveness and children's achievement of language milestones. Child development, 72(3), 748-767.

Tamis-LeMonda, C. S., Kuchirko, Y., \& Song, L. (2014) Why is infant language learning facilitated by parental responsiveness? Current Directions in Psychological Science, 23(2), 121-126.

Taumoepeau, M. (2016) Maternal expansions of child language relate to growth in children's vocabulary. Language Learning and Development, 12(4), 429-446.

Tomasello, M., \& Farrar, M. J. (1986) Joint attention and early language. Child development, 14541463.

Tomasello, M., \& Todd J. (1983) Joint attention and lexical acquisition style. First Language, 4(12), 197-211.

Wake, M., Tobin, S., Girolametto, L., Ukoumunne, O. C., Gold, L., Levickis, P., Sheehan, J., Goldfeld, S. \& Reilly, S. (2011). Outcomes of population based language promotion for slow to talk toddlers at ages 2 and 3 years: Let's Learn Language cluster randomised controlled trial. $B M J, \mathbf{3 4 3}, \mathrm{d} 4741$.

Wallace, I. F., Berkman, N. D., Watson, L. R., Coyne-Beasley, T., Wood, C. T., Cullen, K., \& Lohr, K. N. (2015) Screening for speech and language delay in children 5 years old and younger: a systematic review. Pediatrics, peds-2014.

This article is protected by copyright. All rights reserved. 
Yoder, P.J., Warren, S.F., McCathren R., \& Leew SV. (1998) Does adult resposivity to child behavior facilitate communication development? In: Wetherby, A.M., Warren, S.F., \& Reichle, J., eds. Transitions in Prelinguistic Communication: Transitions in prelinguistic communication: Volume 7 of Communication and language intervention series. Baltimore: Paul H. Brookes; 39-58.

Young, A. R., Beitchman, J. H., Johnson, C., Douglas, L., Atkinson, L., Escobar, M. \& Wilson, B. (2002) Young adult academic outcomes in a longitudinal sample of early identified language impaired and control children. Journal of Child Psychology and Psychiatry, 43(5), 635-645. 
Table 1 Maternal responsive behaviours coding scheme

\begin{tabular}{|c|c|c|c|c|c|}
\hline \multirow{2}{*}{$\begin{array}{l}\text { Maternal Responsive } \\
\text { Behaviour }\end{array}$} & \multirow{2}{*}{ Definition } & \multicolumn{2}{|c|}{ Example of coding } & \multicolumn{2}{|c|}{ Rate per minute $(\mathrm{N}=251)$} \\
\hline & & Child & Parent & Mean (SD) & Range \\
\hline Expansions & $\begin{array}{l}\text { Mother repeats one or all of the child's preceding words } \\
\text { and adds to the child's preceding verbalisation } \\
\text { (Girolametto } \text { et al. 1999; Lasky \& Klopp 1982) }\end{array}$ & "Ball” & $\begin{array}{l}\text { "It's a red } \\
\text { ball" }\end{array}$ & $0.6(0.6)$ & 0 to 3.2 \\
\hline Imitations & $\begin{array}{l}\text { Mother repeats the child's preceding vocalisation or } \\
\text { verbalisation exactly or with a reduction of words } \\
\text { (Girolametto et al. 1999; Lasky \& Klopp 1982) }\end{array}$ & "Ball" & "Ball" & $0.5(0.5)$ & 0 to 3.3 \\
\hline Labels & $\begin{array}{l}\text { Mother labels an object or action, which is the focus of the } \\
\text { child, with the label in the final position of the carrier } \\
\text { phrase (Girolametto et al. 1999; Namy \& Nolan 2004) }\end{array}$ & $\begin{array}{l}\text { Playing with a } \\
\text { toy horse }\end{array}$ & $\begin{array}{l}\text { "That's a } \\
\text { horse" }\end{array}$ & $1.2(0.7)$ & 0 to 4.2 \\
\hline Responsive Questions & Mother asks a 'wh' question (e.g., 'what', 'when', 'who') & Child is & "What's that?" & $0.7(0.5)$ & \\
\hline
\end{tabular}


Table 2 Characteristics of participants followed up and not followed up at 4 years

\section{Variables}

Followed up at 4 Not followed up at years $(\mathrm{N}=208)^{\text {a }} \quad 4$ years $(\mathrm{N}=43)^{\mathrm{b}}$

\section{Child}

Female child, n (\%)

$\begin{array}{cc}98(47.1) & 23(53.5) \\ 12(5.8) & 0(0) \\ 21(10.1) & 6(14.0) \\ 3378.1(618.6) & 3489.9(638.2)\end{array}$

Twin birth, n (\%)

Preterm birth (<37 weeks), n (\%)

3378.1 (618.6)

3489.9 (638.2)

Birth order, n (\%)

First

75 (36.1)

$21(48.8)$

Second

91 (43.8)

15 (34.9)

Third or more

29 (13.9)

$4(9.3)$

Fourth

$11(5.3)$

2 (4.7)

Fifth or more

$2(0.9)$

$1(2.3)$

$24.6(1.2)$

$24.9(1.4)$

Age at 2 year assessment, mean (SD)

198 (95.2)

$36(85.7)$

Both parents

8 (3.8)

$4(9.5)$

One parent

$2(1.0)$

2 (4.8)

Other

$18(8.7)$

$10(23.3)$

Hears non-English language $>10 \mathrm{hrs} /$ week, n (\%)

49 (23.6)

$13(30.2)$

$5.3(3.0)$

$5.6(3.2)$

SSLM vocabulary raw score at 18 months, mean (SD)

34.8 (22.5)

$27.9(20.9)$

SSLM vocabulary raw score at 24 months, mean (SD)

$97.3(14.4)$

CELF-P2 Exp language standard score at 4 yrs, mean (SD)

$94.0(14.1)$

CELF-P2 Rec language standard score at 4yrs, mean (SD)

\section{Mother}

Mother's age at birth of child, mean (SD)

$33.3(4.3)$

$31.8(5.3)$

SEIFA, mean (SD)

Mother's highest level of schooling, n (\%)

Did not complete high school

$39(18.9)$

$16(37.2)$ 
Completed high school

$72(35.0)$

$95(46.1)$

$12(27.9)$

Tertiary degree/postgraduate

Responsive behaviours rate/minute, mean (SD)

Expansions

$0.6(0.6)$

$0.5(0.7)$

Imitations

Interpretations

$0.5(0.5)$

$0.6(0.4)$

$1.2(0.7)$

$0.6(0.5)$

$0.7(0.5)$

Labels

Supportive directives

Responsive questions

SSLM, sure start language measure; SEIFA, socio-economic indexes for areas disadvantage index score; CELF-P2, Clinical Evaluation of Language Fundamentals - Preschool $2^{\text {nd }}$ edition.

${ }^{\mathrm{a}}$ Sample size ranges from 204 to $208 \quad{ }^{\mathrm{b}}$ Sample size ranges from 42 to 43 
Table 3 Linear regressions of CELF-P2 receptive and expressive language outcomes at 4 years by maternal behaviours at 2 years

\begin{tabular}{|c|c|c|c|c|c|c|c|}
\hline \multirow{2}{*}{$\begin{array}{l}\text { Variable } \\
\text { (rate/minute) }\end{array}$} & \multicolumn{3}{|c|}{ Unadjusted models } & \multicolumn{4}{|c|}{ Models adjusted for potential confounders ${ }^{\mathrm{a}}$} \\
\hline & Coefficient & $95 \% \mathrm{CI}$ & $P$ & Coefficient & $95 \% \mathrm{CI}$ & $P$ & Partial $\mathrm{R}^{2}(\%)$ \\
\hline \multicolumn{8}{|l|}{ Receptive Language } \\
\hline Expansions & 7.2 & 4.1 to 10.2 & $<0.001$ & 6.1 & 2.8 to 9.3 & $<0.001$ & 6.5 \\
\hline Imitations & 4.2 & 0.2 to 8.2 & 0.04 & 3.4 & -0.6 to 7.3 & 0.1 & 1.4 \\
\hline Labels & -3.2 & -6.3 to -0.5 & 0.02 & -3.4 & -6.3 to -0.6 & 0.02 & 2.8 \\
\hline Responsive Questions & 3.5 & -0.1 to 7.1 & 0.06 & 3.4 & -0.2 to 6.9 & 0.06 & 1.8 \\
\hline \multicolumn{8}{|l|}{ Expressive Language } \\
\hline Expansions & 8.1 & 5.0 to 11.2 & $<0.001$ & 6.5 & 3.3 to 9.7 & $<0.001$ & 7.7 \\
\hline Imitations & 4.4 & 0.3 to 8.5 & 0.04 & 3.3 & -0.7 to 7.2 & 0.1 & 1.4 \\
\hline Labels & -4.0 & -7.0 to -1.1 & 0.007 & -3.7 & -6.6 to -0.9 & 0.01 & 3.5 \\
\hline Responsive Questions & 3.8 & 0.1 to 7.5 & 0.04 & 3.5 & -0.1 to 7.0 & 0.06 & 1.9 \\
\hline
\end{tabular}


${ }^{a}$ Models adjusted for potential confounder variables including: trial treatment status, gender, age at 4 year follow up, maternal education, SEIFA and birth order ( $N$ ranges from 200 to 204) 
Table 4 Logistic regression analyses for associations of low language status at age 4 with late-talker status and maternal behaviours

\begin{tabular}{|c|c|c|c|c|c|c|c|c|}
\hline \multirow{2}{*}{ Predictor } & \multicolumn{2}{|c|}{ Model 1 (N=197) } & \multicolumn{2}{|c|}{ Model 2 (N=205) } & \multicolumn{2}{|c|}{ Model 3 (N=196) } & \multicolumn{2}{|c|}{ Model 4 (N=194) } \\
\hline & OR $(95 \% \mathrm{CI})$ & $p$ & OR $(95 \% \mathrm{CI})$ & $p$ & OR $(95 \% \mathrm{CI})$ & $P$ & OR $(95 \% \mathrm{CI})$ & $P$ \\
\hline Late-talker status & $5.4(2.6$ to 11.4$)$ & $<0.001$ & & & $2.9(1.2$ to 6.9$)$ & 0.02 & $2.3(0.82$ to 6.3$)$ & 0.1 \\
\hline High use of expansions $(\geq 0.4 / \mathrm{min})$ & & & $0.26(0.12$ to 0.54$)$ & $<0.001$ & $0.43(0.18$ to 1.04$)$ & 0.06 & $0.35(0.13$ to 1.0$)$ & 0.05 \\
\hline High use of labels $(\geq 1.1 / \mathrm{min})$ & & & $2.6(1.3$ to 5.5$)$ & 0.01 & $2.8(1.3$ to 6.2$)$ & 0.01 & $4.5(1.7$ to 11.9$)$ & 0.003 \\
\hline Female & & & & & & & $1.1(0.45$ to 2.7$)$ & 0.8 \\
\hline Preterm birth (<36 weeks) & & & & & & & $1.0(0.2$ to 5.1$)$ & 1.0 \\
\hline Birth weight & & & & & & & $0.60(0.26$ to 1.4$)$ & 0.2 \\
\hline Birth order (ref: First child) & & & & & & & & 0.03 \\
\hline Second child & & & & & & & $4.1(1.4$ to 12.0$)$ & \\
\hline Third child or more & & & & & & & $3.5(0.98$ to 12.6$)$ & \\
\hline Twin birth & & & & & & & $1.9(0.32$ to 11.6$)$ & 0.5 \\
\hline SEIFA disadvantage score & & & & & & & $1.0(0.99$ to 1.0$)$ & 0.2 \\
\hline Mat education level (ref: <Yr 12) & & & & & & & & 0.2 \\
\hline Completed high school & & & & & & & $0.95(0.29$ to 3.1$)$ & \\
\hline Tertiary degree/postgraduate & & & & & & & $0.41(0.12$ to 1.4$)$ & \\
\hline Age at birth of child & & & & & & & $0.91(0.82$ to 1.0$)$ & 0.09 \\
\hline
\end{tabular}


Note: Model 1 AUC (area under the curve) $=0.67$; Model 2 AUC $=0.72$; Model 3 AUC $=0.74$; Model 4 AUC $=0.82$; 'low language status' defined as a score of $>1.25$ standard deviations below the mean for expressive or receptive language on the CELF-P2.

OR, Odds ratio; CI, confidence interval; SEIFA, socio-economic indexes for areas disadvantage index score; NESB, Non-English Speaking Background. 


\section{University Library}

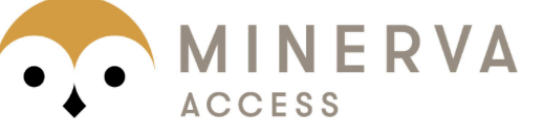

A gateway to Melbourne's research publications

Minerva Access is the Institutional Repository of The University of Melbourne

Author/s:

Levickis, P;Reilly, S;Girolametto, L;Ukoumunne, OC;Wake, M

Title:

Associations between maternal responsive linguistic input and child language performance at age 4 in a community-based sample of slow-to-talk toddlers

Date:

2018-09-01

\section{Citation:}

Levickis, P., Reilly, S., Girolametto, L., Ukoumunne, O. C. \& Wake, M. (2018). Associations between maternal responsive linguistic input and child language performance at age 4 in a community-based sample of slow-to-talk toddlers. CHILD CARE HEALTH AND DEVELOPMENT, 44 (5), pp.776-783. https://doi.org/10.1111/cch.12600.

Persistent Link:

http://hdl.handle.net/11343/284206 